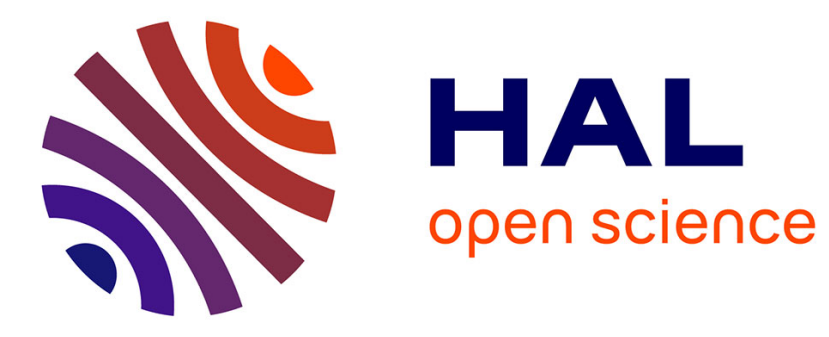

\title{
Design and first experiments on MagPieR, the magnetic microrobot.
}

Soukeyna Bouchebout, Aude Bolopion, Mohamed Kharboutly, Ioan Alexandru Ivan, Joël Agnus, Stéphane Régnier

\section{- To cite this version:}

Soukeyna Bouchebout, Aude Bolopion, Mohamed Kharboutly, Ioan Alexandru Ivan, Joël Agnus, et al.. Design and first experiments on MagPieR, the magnetic microrobot.. International Symposium on OptoMechatronic Technologies., Oct 2012, Paris, France. pp.1-2, 10.1109/ISOT.2012.6403233 . hal-00797881

\section{HAL Id: hal-00797881 \\ https://hal.science/hal-00797881}

Submitted on 7 Mar 2013

HAL is a multi-disciplinary open access archive for the deposit and dissemination of scientific research documents, whether they are published or not. The documents may come from teaching and research institutions in France or abroad, or from public or private research centers.
L'archive ouverte pluridisciplinaire HAL, est destinée au dépôt et à la diffusion de documents scientifiques de niveau recherche, publiés ou non, émanant des établissements d'enseignement et de recherche français ou étrangers, des laboratoires publics ou privés. 


\title{
Design and first experiments on MagPieR, the magnetic microrobot
}

\author{
Soukeyna Bouchebout ${ }^{1}$, Aude Bolopion ${ }^{2}$, Mohamed Kharboutly ${ }^{2}$, Ioan Alexandru Ivan ${ }^{2,3}$, Joël Agnus ${ }^{2}$ \\ and Stéphane Régnier ${ }^{1}$
}

\begin{abstract}
This article deals with the design, the actuation and the control of magnetic microrobots. The interest in such microscale robots actuated by remote force fields is increasing since a large range of application fields could benefit from these small size manipulators. However major scientific challenges such as the optimization of the actuation platform, or the reduction of the adhesion between the robot and the substrate must still be overcome to perform complex micromanipulations. This article presents an example of a magnetic microrobot, MagPieR. Its design, fabrication, actuation and control are detailed. First experiments are presented, and the issues that must still be overcome are highlighted.
\end{abstract}

\section{INTRODUCTION}

The manipulation of micrometer size objects is of utmost importance for a wide range of application domains, from electronics to biology. Two different approaches, contact and non contact manipulation, are currently considered. Contact manipulation uses tools, such as tips or grippers, directly inspired from macroscale systems. However, due to the scale reduction adhesion forces become predominant over gravity and limit the precision of object release. Non contact manipulation consists in controlling objects with force fields created by remote sources. The most common techniques are laser trapping [1], dielectrophoresis [2], [3] and magnetic actuation [4], [5]. Among them magnetic actuation is promising since high forces can be generated, and only magnetic objects are subject to magnetic fields. Magnetic microrobots can thus be used to selectively manipulate objects.

In this article a magnetic microrobot, MagPieR, is presented. The main issues that must be addressed for the design, the actuation and the control of such microrobotic platforms are detailed. The current system and the first experiments are presented in Sec. II. Challenges that must still be overcome are highlighted in Sec. III. Sec. IV concludes the paper.

\section{The MagPieR Microrobot}

The MagPieR microrobot is rectagular, with dimensions $388 \mu \mathrm{m} \times 300 \mu \mathrm{m} \times 224 \mu \mathrm{m}$ (fig. 1(a)). It is composed of two different layers:

- a $24 \mu \mathrm{m}$ thick layer of nickel, which is a ferromagnetic material that enables to move the robot using magnetic fields

${ }^{1}$ Institut des Systèmes Intelligents et de Robotique, Université Pierre et Marie Curie, CNRS UMR 7222, 4 Place Jussieu, 75005 Paris, France. bouchebouteisir.upmc. fr

2 Institut FEMTO-ST, UFC, ENSMM, UTBM, CNRS UMR 6174, 24 rue Alain Savary, 25000 Besançon, France.

${ }^{3}$ Valahia University of Targoviste, Electr. Eng. Fac. B-Dul Unirii 18-20, Targoviste 130082, Romania
- a $200 \mu \mathrm{m}$ thick layer of PMN-PT, which is a piezoelectric layer

The robot is fabricated using classical cleanroom microfabrication process. The PMN-PT substrate is cut into half-a- $\mathrm{cm}^{2}$ plates. A layer of chromium and copper is sputtered to ensure the conductivity for the electrodeposition of the nickel and the mechanical coherence. The nickel layer is then electroplated. The microrobots are obtained by saw dicing the whole substrate into rectangular samples of the desired dimensions. Trenches are made by saw on top of the nickel layer.

When a magnetic field is applied on the robot it experiences a force $F$ and a torque $T$ :

$$
\begin{aligned}
F & =V(M \cdot \nabla) B \\
T & =V M \times B
\end{aligned}
$$

where $V$ is the volume of the ferromagnetic part of the robot, $M$ is its internal magnetization and $\mathrm{B}$ is the magnetic field. The force tends to attract the robot towards strong values of magnetic field. The torque aligns the magnetization of the robot along with the magnetic field lines.

To generate a controlled magnetic field an actuation platform composed of four coils is used (fig. 1(b)). The coils require less than $1 \mathrm{~A}$ to activate the micro-robot. The coils generate a magnetic field that allows $3 \mathrm{DoF}$ to the microrobot: 2 translations in the $\mathrm{x}$ and $\mathrm{y}$ directions, and a rotation in the -x,y- plane. The MagPieR moves inside a capacitor. The bottom electrode is the arena substrate itself, and the top electrode is an optically transparent conductive glass (ITO glass) allowing a visualization of the scene from above. The observation of the MagPieR is done by a top situated high speed camera (1000 frames per second). The micro-robot then moves in a dry environment. A detailed description of the whole system is available in [6].
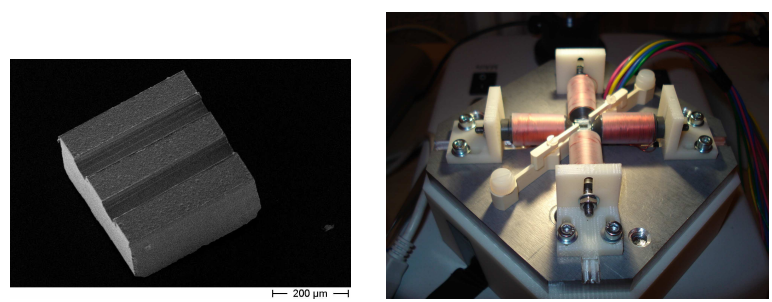

(a) The MagPieR microrobot, (b) The actuation system composed composed of a nickel layer and of four coils a PMN-PT layer

Fig. 1. The magnetic micromanipulation platform 
Two different experiments have been performed to test the microrobot performances and to participate to the NIST IEEE Mobile Microrobotics Challenge held during the ICRA Conference. The first one is to evaluate the velocity of the microrobot, by moving it from one side of the arena to the other one as fast as possible (fig 2). It takes $28 \mathrm{~ms}$ to the robot to go through a $2 \mathrm{~mm}$ distance. The second experiment consists in performing an $\infty$ shape trajectory in automated mode. To control the microrobot the workspace has been divided into eight different areas. A sequential command has been implemented to move the microrobot from one of the area to the next one. Good results have been obtained since the trajectory has been performed in less than $0.5 \mathrm{~s}$. However this approach does not enable a precise trajectory tracking.

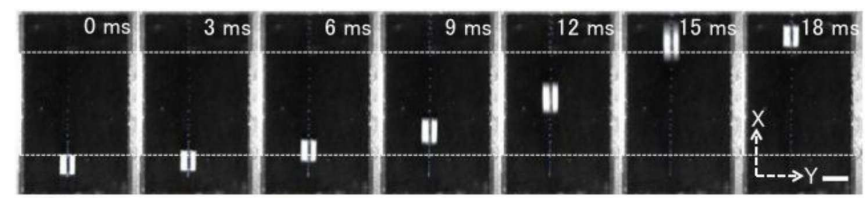

Fig. 2. '2mm dash' experiment performed for the 2010 NIST IEEE Mobile Microrobotics Challenge [6]

\section{FUTURE DIRECTIONS}

Several challenges must still be addressed to perform complex micromanipulation tasks and to ensure precise positionning.

The first issue is the optimisation of the actuation system. The dimensions of the coils should be determined to ensure that a high force can be applied on the robot. The time response should be minimized to enable high frequency operations. In addition, the position of the coils should be optimized to ensure that any area of the workspace is reachable. It is also important to avoid overwhelming non linearities of the magnetic field. To perform complex manipulation 3 degrees of freedom of displacements are necessary. At least two additional coils should be added to perform controlled up and down motion.

Compared to most of the current magnetic microrobot systems MagPieR is actuated in air, and not in a liquid environment [4], [5]. This enables to reach higher velocities since the drag force is considerably reduced, however the adhesion between the robot and the substrate becomes a major issue, and limits the positioning precision. To reduce this phenomena it is possible to the use the piezoelectric effect. High frequency, high voltage impulses on the bottom electrode can actuate the piezoelectric effect to free the micro-robot from adhesion. However experiments should be carried out to precisely determine the influence of each parameters (intensity and frequency of the impulses) to control the vibrations.

The control law should also be improved since in the current system only one coil at a time is actuated. The control of several coils simultaneously will enable to perform more complex trajectories. To ensure a stable control law it is necessary to track the robot at high frequency. The use of an event based camera [7], that records only changes of contrast will enable a fast tracking (frequencies higher than $1 \mathrm{kHz}$ can be reached for this sensor).

\section{CONCLUSION}

This paper presents a magnetic microrobot, MagPieR. The design, actuation and control of this robot are detailed. First experiments have been performed, and show promising results. In particular they confirm that due to the small inertia at this scale high velocities can be obtained. However the precision of trajectory tracking is still limited.

Future works include the optimisation of the actuation platform to ensure that high forces can be applied on the robot, while decreasing the time response of the system and improving the linearity of the magnetic field. Adhesion between the microrobot and the substrate should be reduced, and adapted control laws should be implemented to enable complex micromanipulations.

\section{ACKNOWLEDGMENT}

This work was supported by the EU FP7-SP3-People Program under Grant No: PIEF-GA-2008-219412 (NewMicroRobotic Systems featuring Piezoelectric Adaptive MicroStructures for Sensing and Actuating, with Associated Embedded Control: MicroPAdS) and by the French National Agency of Research, through the LEMA project.

\section{REFERENCES}

[1] F. Arai, K. Onda, R. Iitsuka, and H. Maruyama, "Multi-beam laser micromanipulation of microtool by integrated optical tweezers," in IEEE International Conference on Robotics and Automation, 2009, pp. $1832-1837$.

[2] A. Subramanian, B. Vikramaditya, B. Nelson, D. Bell, and L. Dong, "Dielectrophoretic micro/nanoassembly with microtweezers and nanoelectrodes," in International Conference on Advanced Robotics, 2005, pp. $208-215$.

[3] M. Kharboutly, M. Gauthier, and N. Chaillet, "Modeling the trajectory of a micro particle in a dielectrophoresis device." IEEE International Conference on Robotics and Automation, 2010.

[4] M. P. Kummer, J. J. Abbott, B. E. Kratochvil, R. Borer, A. Sengul, and B. J. Nelson, "OctoMag: an electromagnetic system for 5-DOF wireless micromanipulation," IEEE Transactions on Robotics, vol. 26, no. 6, pp. 1006-1017, 2010.

[5] E. D. Diller, S. Floyd, C. Pawashe, and M. Sitti, "Control of multiple heterogeneous magnetic microrobots in two dimensions on nonspecialized surfaces," IEEE Transactions on Robotics, vol. 28, no. 1, pp. 172$182,2012$.

[6] I. Ivan, G. Hwang, J. Agnus, M. Rakotondrabe, N. Chaillet, and S. Régnier, "First experiments on magpier: A planar wireless magnetic and piezoelectric microrobot," in IEEE International Conference on Robotics and Automation, 2011, pp. 102 - 108.

[7] Z. Ni, A. Bolopion, J. Agnus, R. Benosman, and S. Régnier, "Asynchronous event-based visual shape tracking for stable haptic feedback in microrobotics," IEEE Transactions on Robotics, 2012. 